\title{
Environmental conditions of Jiaozhou Bay in 1980
}

\author{
Dongfang Yang ${ }^{1,2,3, a}$, Fengyou Wang ${ }^{1,2, b, c}$, Sixi Zhu ${ }^{1,2}$, Xiaoli Zhao ${ }^{1,2}$ and \\ Yunjie $\mathrm{Wu}^{1,2}$
}

${ }^{1}$ Research Center for Karst Wetland Ecology, Guizhou Minzu University, Guiyang 550025, China;

${ }^{2}$ College of Chemistry and Environmental Science, Guizhou Minzu University, Guiyang 550025, China;

${ }^{3}$ North China Sea Environmental Monitoring Center, SOA, Qingdao 266033, China.

adfyang_dfyang@126.com, ${ }^{b}$ corresponding author, cfywang@163.com.cn

Keywords: Heavy metal, Petroleum hydrocarbon, Environmental condition, Pollution source, Transfer process, Jiaozhou Bay.

\begin{abstract}
Environmental conditions of many marine bays in China have been seriously polluted along with the rapid developing of economic after the reform and opening up. This paper revealed the environmental conditions of Jiaozhou Bay, Shandong Province, Eastern China based on the analyzing the content, pollution level, pollution source and transfer process of heavy metals of $\mathrm{Hg}$, $\mathrm{Pb}$ and $\mathrm{Cd}$, as well as petroleum hydrocarbon (PHC). Results showed that pollution levels of $\mathrm{Cd}$ and $\mathrm{Pb}$ were very slight in 1980, yet the pollution levels of $\mathrm{Hg}$ and $\mathrm{PHC}$ were slight. The environmental conditions of Jiaozhou Bay were beginning to be deteriorated in 1980 . Cd in Jiaozhou Bay was mainly sourced by marine current from other regions. $\mathrm{Pb}, \mathrm{Hg}$ and $\mathrm{PHC}$ sourced from both anthropogenic activities and atmosphere deposition in study area. The temporal and spatial variations of the pollutants were determined by their transfer processes, which were mainly determined by anthropogenic activities, marine organism and hydrology.
\end{abstract}

\section{Introduction}

Environmental pollution has long been a world wide issue due to the lagging of environmental protection behind the rapid increasing of economic and human population. A large amount of pollutants are discharged to the environment and causing various risks to both ecological environment and human being. Marine is the sink of pollutants. Understanding the content, pollution level, pollution source and transfer process of the critical pollutants in marine environment is essential to environmental research, as well as pollution control and environmental remediation [1-12].

Jiaozhou Bay $\left(35^{\circ} 55^{\prime}-36^{\circ} 18^{\prime} \mathrm{N}, 120^{\circ} 04^{\prime}-120^{\circ} 23^{\prime} \mathrm{E}\right)$ is a semi-closed bay located in Shandong Province, eastern China, and is surrounding by cities of Qingdao, Jiaozhou and Jiaonan (Fig. 1). The size of the bay, width of bay mouth, and average water depth are $446 \mathrm{~km}^{2}, 2.5 \mathrm{~km}$, and $7 \mathrm{~m}$, respectively. This bay has more than ten inflow rivers, such as Dagu River, Loushan River, Licun River and Haibo River, most of which are playing roles of discharging channels of pollutants. Previous studies had showed that this bay was polluted buy heavy metals, petroleum hydrocarbon and pesticides [7-10].

In order to provide background information of environmental conditions of Jiaozhou Bay at the early stage of the reform and opening up, and to provide basis for environmental research, as well as for practical work on pollution control and environmental remediation. This paper revealed the environmental conditions of Jiaozhou Bay, Shandong Province, Eastern China based on the analyzing the content, pollution level, pollution source and transfer process of heavy metals of Hg, $\mathrm{Pb}$ and $\mathrm{Cd}$, as well as petroleum hydrocarbon (PHC) based on the investigation on environmental conditions in surface waters in 1980. 


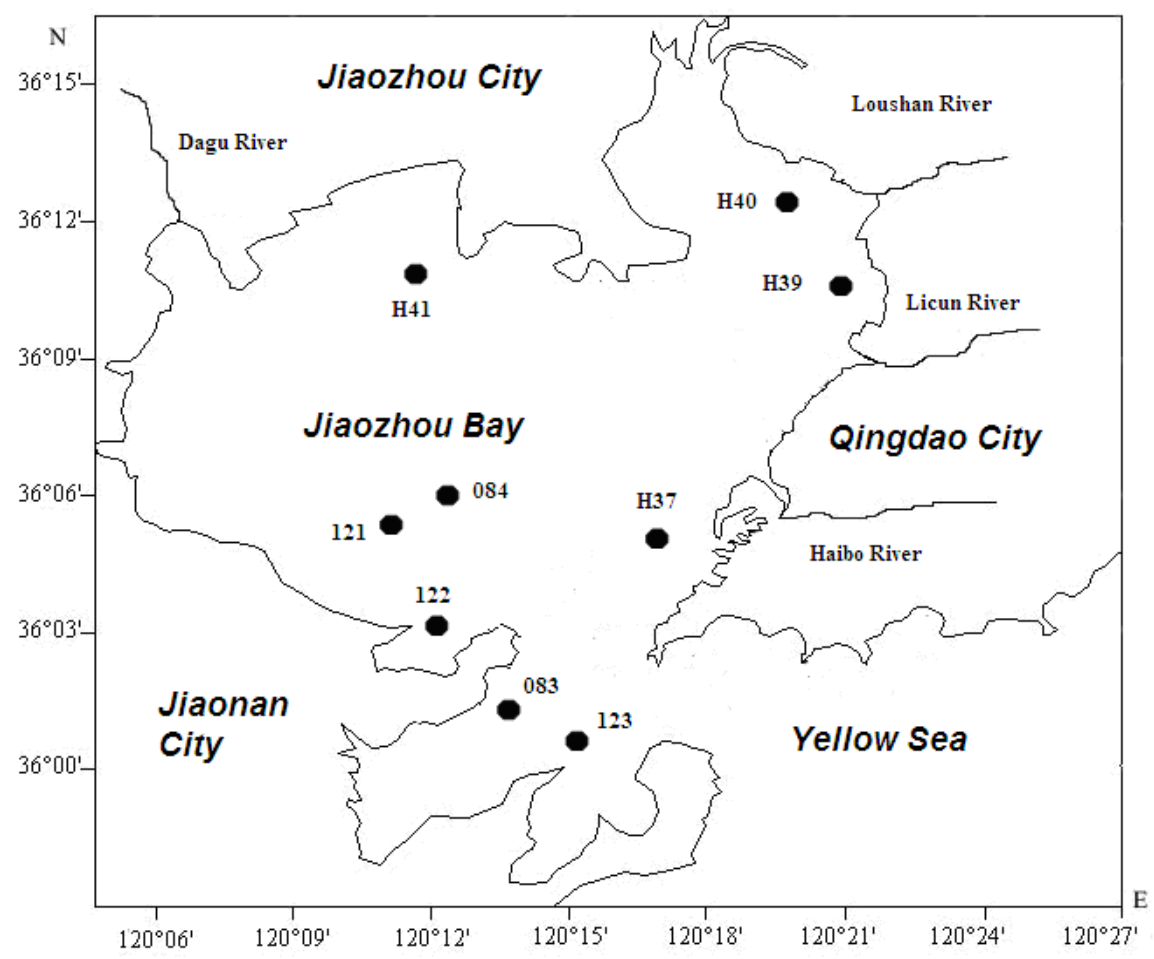

Fig. 1 Geographical location and monitoring sites of Jiaozhou Bay

\section{Contents and pollution levels}

The contents of $\mathrm{Cd}$ and $\mathrm{Pb}$ in different seasons in surface waters in Jiaozhou Bay were $0.00-0.48 \mu \mathrm{g} \mathrm{L}^{-1}$ and $0.07-2.71 \mu \mathrm{g} \mathrm{L} \mathrm{L}^{-1}$, respectively. In according to Sea water quality standard (GB 3097-1997) of China, $\mathrm{Cd}$ and $\mathrm{Pb}$ contents in all of the monitoring sites were confirmed to Grade $\mathrm{I}$. In comparison, $\mathrm{Hg}$ contents were showing significant variations in different regions. Hg contents in estuaries of Haibo River, Licun River and Loushan River ranged from 0.08-13.04 $\mu \mathrm{g} \mathrm{L}^{-1}$, which were more higher than the upper limit of Grade III, while for other regions were confirmed to Grade I. PHC contents in all of the monitoring sites were confirmed to Grade III in June and September. In July and October, PHC contents in estuaries of Haibo River, Licun River and Loushan River were confirmed to Grade III, while for other sites were Grade II. The pollution levels of $\mathrm{Cd}$ and $\mathrm{Pb}$ were very slight in 1980. However, the pollution levels of Hg and PHC were slight pollution, especially in regions in estuaries of the major inflow rivers. Meanwhile, the environmental conditions of Jiaozhou Bay were showing significant seasonal variations (Table 1). In generally, the pollution levels of different pollutants were in order of $\mathrm{Cd}<\mathrm{Pb}<\mathrm{Hg}<\mathrm{PHC}$.

Table 1 Seasonal variations of environmental conditions of Jiaozhou Bay

\begin{tabular}{cccc}
\hline Pollutant & Spring & Summer & Autumn \\
\hline $\mathrm{Cd}$ & Non-pollution & Non-pollution & Non-pollution \\
$\mathrm{Pb}$ & Very slight pollution & Slight pollution & Non-pollution \\
$\mathrm{Hg}$ & Slight pollution & Slight pollution & Slight pollution \\
$\mathrm{PHC}$ & Slight pollution & Slight pollution & Slight pollution \\
\hline
\end{tabular}

\section{Pollution sources}

Based on the analyzing on the spatial and temporal variation of the contents, the pollution sources of these pollutants could be defined. For Cd, there was only one major pollution source, that was marine current itself. Cd was transported by marine current, and was transferred to the bay mouth and the bay sequentially. For $\mathrm{Pb}$ and $\mathrm{Hg}$, the major pollution sources were anthropogenic activities and atmosphere deposition. Streams such as Haibo River, Licun River and Loushan River 
were the major channels for the input of $\mathrm{Pb}$ and $\mathrm{Hg}$ to Jiaozhou Bay. PHC was mainly generated from anthropogenic activities in study region, and the inflow rivers were also the major input channels. These findings indicated that Cd in Jiaozhou Bay was not sourced by anthropogenic activities in study area, but was input by marine current from other regions. However, $\mathrm{Pb}, \mathrm{Hg}$ and PHC were sourced from both anthropogenic activities and atmosphere deposition in study area.

\section{Transfer processes}

Pollutants of $\mathrm{Cd}, \mathrm{Pb}, \mathrm{Hg}$ and $\mathrm{PHC}$ etc Could be considered as substances. We proposed a concept of substance transfer process in waters, which was involving by three stages of 1) substances were exported from pollution sources to waters of the bay, 2) substances were transferred in surface waters, and 3) substances were transferred from surface water to bottom waters. The grow and reproduction of marine organism such as phytoplankton and zooplankton were beginning to increase in spring, and were reaching the climax in summer [7]. The activities of marine organism were producing s large amount of colloids, which could be enhancing the absorption capacity of suspended particulate matters in waters. Hence, these substances were absorbed and transferred from surface waters to bottom waters by means of gravitational force and hydrodynamic force. Therefore, the contents of these substances were decreasing with time during spring to summer, and were accumulated in the sea bottom simultaneously. In generally, the temporal and spatial variations of the pollutants were determined by their transfer processes, which were mainly determined by anthropogenic activities, marine organism and hydrology.

\section{Conclusions}

The pollution levels of $\mathrm{Cd}$ and $\mathrm{Pb}$ were very slight in 1980, yet the pollution levels of $\mathrm{Hg}$ and PHC were slight pollution, especially in regions in estuaries of the major inflow rivers. The environmental conditions of Jiaozhou Bay were beginning to be deteriorated in 1980. The pollution levels of different pollutants were in order of $\mathrm{Cd}<\mathrm{Pb}<\mathrm{Hg}<\mathrm{PHC}$. Cd in Jiaozhou Bay was mainly sourced by marine current from other regions. $\mathrm{Pb}, \mathrm{Hg}$ and $\mathrm{PHC}$ sourced from both anthropogenic activities and atmosphere deposition in study area. The temporal and spatial variations of the pollutants were determined by their transfer processes, which were mainly determined by anthropogenic activities, marine organism and hydrology.

\section{Acknowledgement}

This research was sponsored by Doctoral Degree Construction Library of Guizhou Nationalities University, Education Ministry's New Century Excellent Talents Supporting Plan (NCET-12-0659), Project of Outstanding Technological Educators of Governor of Guizhou ([2012]71), Project of Low Carbon Technology Plan of Guiyang (2012205]), Project of Science and Technology Foundation of Guiyang (LKM[2012]05), Special Research Projects of High Level Talents of Guizhou Province (TZJF-2011- 44), and Research Projects of Guizhou Nationalities University ([2014]02).

\section{References}

[1] Yang DF, Cao HR, Gao ZH, et al.: Marine Science, Vol. 27 (2008), p. 37-39. (in Chinese)

[2] Yang DF, Gao ZH, Sun JY, et al.: Coastal Engineering, Vol. 27(2008), p. 48-53. (in Chinese)

[3] Yang DF, Su C, Gao ZH, et al.: Chinese Journal of Oceanology and Limnology, Vol. 26 (2008), p: 296-299.

[4] Yang DF, Chen Y, Wang H, et al.: Coastal Engineering, Vol. 29 (2010), p. 73-82. (in Chinese)

[5] Yang DF, Gao ZH, Cao HR, et al.: Coastal Engineering, Vol. 27 (2008), p. 65-71. (in Chinese) 
[6] Yang DF, Zhang YC, Zou J, et al.: Open Journal of Marine Science, Vol. 2 (2011), p. 108-112

[7] Yang DF, Chen Y, Chang YX, et al.: Coastal Engineering, Vol. 32 (2013), p. 68-78. (in Chinese)

[8] Yang DF, Guo JH, Zhang YJ, et al.: Journal of Water Resource and Protection, Vol. 3(2011), p. 41-49.

[9] Yang DF, Wang LL, Gao ZH, et al.: Marine Science, Vol. 28 (2009), p. 501-505. (in Chinese)

[10] Yang DF, Sun PY, Chen C, et al.: Coastal Engineering, Vol. 32 (2013), p. 60-72. (in Chinese)

[11]Chen Y, Zhang JY, Guo JH, et al.: Ocean Development and Management, Vol. 30 (2013), p. 81-83. (in Chinese)

[12] Yang DF, Gao ZH, Sun PY, et al.: Coastal Engineering, Vol. 28 (2009), p. 69-77. (in Chinese) 